\title{
AVALIAÇÃO DA AÇÃO DE EXTRATOS VEGETAIS SOBRE A FORMAÇÃO DE BIOFILMES POR Candida albicans
}

\section{EVALUATION OF THE PLANT EXTRACTS ACTION ON BIOFILM FORMATION BY Candida albicans}

\author{
Noara Taline Pereira dos Reis ${ }^{1}$ \\ Taline Chaves Lelis ${ }^{2}$ \\ Alexandre Tourino Mendonça $\mathrm{a}^{3}$ \\ Jorge Kleber Chavasco ${ }^{4}(\mathrm{PQ})$
}

\author{
${ }^{1}$ Acadêmica bolsista do Probic UNIFAL-MG \\ ${ }^{2}$ Acadêmica da UNIFAL-MG \\ ${ }^{3}$ Professor da UNINCOR -Universidade Vale do Rio Verde-Três Corações -MG \\ ${ }^{4}$ Departamento de Microbiologia e Imunologia - Universidade Federal de Alfenas - UNIFAL-MG - Alfenas, MG
}

\author{
Autor Correspondente \\ Prof. Dr. Jorge Kleber Chavasco \\ Universidade Federal de Alfenas (UNIFAL-MG) \\ Rua Gabriel Monteiro da Silva 700 \\ 37130-000-Alfenas-MG-Brasil \\ Email: jkchavasco@uol.com.br
}

RESUMO: O biofilme é constituído por uma comunidade diversificada de microrganismos aderida sobre superfícies bióticas e abióticas, formado inclusive por Candida albicans. Na cavidade bucal, a presença de biofilme constitui o primeiro passo para o desenvolvimento de cárie dentária e doença periodontal, o que torna necessário a avaliação da eficácia de novas alternativas, como o uso de extratos vegetais, para promover a prevenção. Foram avaliadas as atividades inibitórias de extrato de folha de jabuticabeira (Myrciaria cauliflora) e extrato de folha de goiabeira (Psidium guajava L) na formação de biofilme por Candida albicans, pois esta levedura é largamente encontrada associada as doenças da boca. Foram utilizadas microplacas para cultivo da levedura e para avaliar o grau de inibição da formação do biofilme através da aderência verificada pela turvação no leitor de ELISA. Nenhum dos extratos inibiu a formação do biofilme nas concentrações utilizadas.

Palavras chave: Biofilme. Inibição. Extrato de jabuticabeira (Myrciaria cauliflora). Extrato de goiabeira (Psidium guajava L). Candida albicans.

\begin{abstract}
The biofilm consists of a diverse community of microorganisms attached on biotic and abiotic surfaces, formed by Candida albicans. In the oral cavity, the presence of biofilm is the first step towards the development of dental caries and periodontal disease, which makes it necessary to assess the effectiveness of new alternatives, such as the use of plant extracts, to promote prevention. We evaluated the inhibitory activities of the extract of the jabuticabeira leaf (Myrciaria cauliflora) and leaf extract of guava (Psidium guajava L) in biofilm formation by Candida albicans, as this yeast is generally associated with diseases of the mouth. Microplates were used for yeast cultivation and to assess the degree of biofilm formation inhibition through the tack checked by turbidity in the ELISA reader. None of the extracts inhibited biofilm formation at the concentrations used.
\end{abstract}

Keywords: Biofilm. Inhibition. Extract of jabuticabeira (Myrciaria cauliflora). Extract of guava (Psidium guajava L). Candida albicans. 


\section{INTRODUÇÃO}

Candida albicans é um microrganismo comensal, isolado com freqüência da cavidade bucal de indivíduos saudáveis. As diferentes formas de candidose bucal, superficial ou sistêmica, são freqüentemente associadas a biofilmes formados por Candida albicans. (RAMAGE at al., 2005). Essas leveduras têm sido isoladas de biofilmes dentários (NIKAWA et al., 2003), demonstrando que os mesmos podem estar correlacionados no desenvolvimento de cáries e na patogênese de doenças periodontais. (JARVENSIVU et al., 2004).

A candidíase ou candidose é uma infecção fúngica produzida pela levedura Candida albicans a qual vive nas mucosas e só causa doenças quando existem condições que favoreçam o seu crescimento. É a mais comum das infecções fúngicas que afetam a boca; podem desenvolver-se em qualquer superfície da mucosa e normalmente, em pacientes infectados pelo HIV, apresentam a lesão no palato duro e palato mole (AIDS, 2003).

\begin{tabular}{lcr}
\multicolumn{1}{c}{ Biofilmes } & são formados & por \\
comunidades & heterogêneas & de \\
microrganismos, que se acumulam em & em \\
superfícies, organizadas tridimensionalmente, \\
e embebidas, em uma matriz extracelular de \\
polímeros (MARSH, 2004). Os biofilmes \\
apresentam características de \\
desenvolvimento e traços fenotípicos únicos, \\
quando comparados com as mesmas células
\end{tabular}

crescidas em culturas planctônicas, os que os tornam mais resistentes a agentes antimicrobianos e fatores imunes do hospedeiro (DAVEY E O'TOOLE, 2000).

Diversos produtos de origem vegetal mostram ser potencialmente interessantes, no que se refere a sua atividade antimicrobiana (YANAGIDA A, 2000). Dentre estas se destacam a goiabeira e a jabuticabeira.

\section{A planta Pisidium guajava L.,} conhecida popularmente como goiabeira, se apresenta na natureza em forma de arbusto perene da família das Mirtáceas. É uma árvore frutífera, originária das Américas Central e do Sul, cultivada em todos os países de clima tropical. Na medicina popular é utilizada para cólicas, colite, diarréia e dor de barriga (VENDRUSCULO et al., 2005; TÔRRES et al., 2005). Suas folhas apresentam a seguinte composição química: taninos (9-10\%), óleo essencial $(90,3 \%)$ rico em cariofileno, nerolidiol, b-bisaboleno, aromadendreno, p-selinemo, a-pinemo e 1,8cineol; triterpenóides (ácido oleanólico, ursólico, catecólico, guaiavólico, maslínico), b-sitosterol. O caule possui taninos numa concentração de 12 a 30\% (ALONSO, 1998). SATO et al. (2000), pesquisando a atividade antifúngica de extratos de plantas para assepsia e esterilização, encontraram atividade antimicótica de Psidium guajava frente a Aspergillus fumigatus M008. PESSINI et al. (2003) verificaram que a espécie Psidium guajava foi uma das mais 
ativas frente às leveduras C. albicans, $C$. krusei, C. parapsilosis e C. tropicalis.

A espécie Myrciaria cauliflora conhecida, popularmente, como jabuticaba paulista, jabuticaba assú (ASCHERI et al., 2006) ou jabuticaba ponhem (BRUNINI et al., 2004), é uma planta nativa do Brasil, da Mata Atlântica, que vegeta diversos solos, podendo ser encontrada desde o Pará ao Rio Grande do Sul. Os estudos fitoquímicos da jabuticaba encontrados na literatura são poucos, estando reportada a presença de ácido ascórbico, taninos e glicosídeos cianidínicos e peonidínicos (REYNERTSON, 2006). MACEDO-COSTA (2008) observou resultados positivos do extrato do caule de Myrciaria cauliflora Berg. sobre cepas de Lactobacillus casei e Streptococcus mitis.

O estudo de compostos e extratos de produtos naturais tem sido realizado visando a obtenção de agentes antimicrobianos que possibilitem a prevenção de doenças bucais, especialmente as relacionadas ao biofilme dental, com o máximo de efetividade e o mínimo de agressão ao organismo (BOTELHO et al., 2007). A busca por agentes antimicrobianos com aplicabilidade terapêutica e economicamente viáveis tornase um evento importante na promoção da saúde bucal da população.

\section{MATERIAIS E MÉTODOS}

Foram avaliadas as atividades inibitórias dos extratos hidroetanólicos da folha de jabuticabeira (Myrciaria cauliflora) e de folha de goiabeira (Psidium guajava $\mathrm{L}$ ) na formação de biofilme por Candida albicans. Foram utilizados 11 isolados de Candida albicans oriundos de pacientes com candidose eritematosa, mantidos na micoteca do Laboratório de Micologia do ICB da USP, em São Paulo. As amostras foram mantidas em Agar Sabouraud dextrose. Para a realização dos testes utilizou-se o seguinte protocolo: para obtenção dos extratos hidroetanólicos foram pesados $200 \mathrm{~g}$ de folhas e adicionados $800 \mathrm{~mL}$ de etanol a $70 \%$. A maceração foi realizada por 5 dias com uma agitação diária. Após 5 dias os extratos foram filtrados, concentrados em rotaevaporador e liofilizados. Os extratos liofilizados das folhas de jabuticabeira e goiabeira, foram utilizados em concentrações decrescentes em meio de cultura Caldo Sabouraud Dextrose 2 vezes concentrado em microplacas de 96 cavidades próprias para cultivo celular e incubadas a $37^{\circ} \mathrm{C}$ por 96 horas juntamente com a amostra da levedura. As diluições de P. guajava L foram realizadas a partir da concentração de $62,0 \mathrm{mg} / \mathrm{mL}$ ou seja 31,$0 ; 16,5 ; 8,25 ; 4,12$; 2,06 e $1,03 \mathrm{mg} / \mathrm{mL}$. As diluições de $M$. cauliflora foram realizadas a partir da concentração de $42,6 \mathrm{mg} / \mathrm{mL}$ ou seja 21,3 ; 10,$6 ; 5,3 ; 2,66 ; 1,33$ e 0,66 mg/mL. Após o tempo de incubação da microplaca a $37^{\circ} \mathrm{C}$ por 96 horas em estufa sob agitação, o meio de cultura foi removido e os poços foram lavados com água destilada para remoção de células não aderidas. Solução de cristal violeta a 0,5 
$\%$ foi adicionada aos poços por 20 minutos. As placas foram lavadas com água destilada e adicionou-se 200 microlitros de álcool a $96^{\circ} \mathrm{GL}$ em cada poço. A formação de biofilme foi avaliada em um leitor de ELISA e considerada positiva quando a densidade óptica a $570 \mathrm{~nm}$ fosse maior ou igual a 0,2 (WAKIMOTO, 2004). Paralelamente foram feitos os seguintes controles: esterilidade do extrato, esterilidade do meio de cultura, promoção do crescimento e inibição pela solução de clorexidina a $0,12 \%$.

\section{RESULTADOS E DISCUSSÃO}

Vários agentes antimicrobianos vêm sendo estudados, com o objetivo de inibir ou reduzir a formação do biofilme dental, crescimento bacteriano, e consequentemente a adesão de microrganismos à superfície dentária (KORNMAN, 1986; MORAN et al., 2001; RODRIGUES JÚNIOR et al., 1998).

No presente artigo, buscou-se verificar a ação dos extratos hidroetanólicos de Psidium guajava L e Myrciaria cauliflora no controle da formação de biofilme por Candida albicans.

Para comprovação e avaliação do crescimento de biofilme foram feitos testes com 11 amostras de Candida albicans. Verificou-se através do leitor de ELISA que em todas essas 11 amostras houve crescimento e formação de biofilme, considerado positivos valores acima de $0,2 \mathrm{de}$ absorbância. As amostras de leveduras 12 IAF e 16- FBC obtiveram os maiores valores de crescimento, médias 0,962 e 2,830, respectivamente.

Segundo WAKIMOTO, 2004, a inibição do biofilme poderia ser testada utilizando microplacas para cultivo celular juntamente com extratos. Com esta técnica testamos a inibição da formação do biolfime de Candida albicans com extratos vegetais da folha de goiabeira (Psidium Guajava L) e da folha de jabuticabeira (Myrciaria Cauliflora). De acordo com as leituras comparadas com o controle de clorexidina a $0,12 \%$ que inibiu a formação de biofilme, verificou-se que esses extratos não inibiram a formação de biofilme por nenhum dos isolados testados. A clorexidina tem sido muito utilizada no controle de formação do biofilme dental, alterando a composição bacteriana do biofilme supragengival produzindo uma redução significante sobre o número de microrganismos por períodos prolongados. Segundo BEIGHTON; DECKER; HOMER (1991) este fato ocorre devido à sua liberação lenta na cavidade bucal (maior substantividade ou adesividade) e consequentemente a sua ação inibidora sobre as enzimas glicosídicas e proteolíticas.

SATO et al. (2000), PESSINI et al. (2003) e ALVES M. P. et al. (2006), pesquisaram a atividade antifúngica de extratos de plantas para assepsia e esterilização encontrando atividade antimicótica de Psidium guajava frente a algumas amostras e verificaram que a espécie Psidium guajava foi uma das mais 
ativas frente às leveduras $C$. albicans, $C$. krusei, C. parapsilosis e C. tropicalis. MACEDO-COSTA (2008) observou resultados positivos do extrato do caule de Myrciaria cauliflora Berg. sobre cepas de Lactobacillus casei e Streptococcus mitis. MACEDO-COSTA, M.R. et al. (2009) concluiu que o extrato de Myrciaria cauliflora produziu uma significante atividade bacteriostática in vitro sobre linhagens de $S$. mitis, S. mutans, S. sanguinis, S. oralis, $S$. salivarius e L. casei, bactérias do biofilme dental. Nestes trabalhos verificou-se atividade inibitória dos extratos Psibdium Guajava L e Myrciaria Cauliflora frente a diversos microrganismos, inclusive $C$. albicans, mas no nosso trabalho não constatamos ação inibitória no crescimento e na formação de biofilmes por Candida albicans. A justificativa, provavelmente, pode ser pelo fato das plantas serem de outras regiões, ou utilizado concentrações diferentes dos extratos nos testes, o que interfere nos nossos resultados. De acordo com as leituras comparadas com o controle de clorexidina a $0,12 \%$ no leitor de ELISA, verificou-se que os extratos de jabuticabeira e goiabeira não inibiram a formação de biofilme por Candida albicans. (FIGURA 01).
FIGURA 01- Avaliação da ação inibitória dos extratos hidroetanólicos das folhas de Myrciaria cauliflora e Psidium Guajava L. sobre o crescimento da formação de biofilme por Candida albicans.

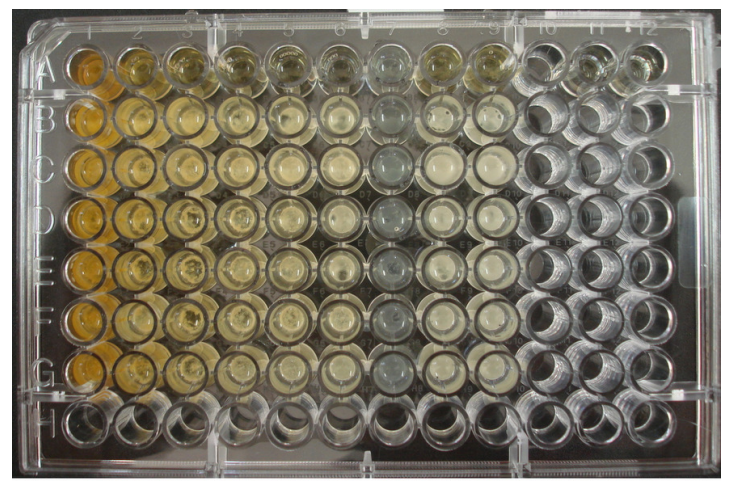

Legenda: Fileira A - Colunas 1 a 6- Controle dos extratos nas concentrações de diluições 1:2, 1:4, 1:8, 1:16, 1:32 e 1:64. Colunas 8 e 9- Controle de esterilidade dos extratos (CEE). Colunas 11 e 12Controle de esterilidade do meio (CEM). Fileiras B a G- Colunas 1 a 6- Controle de inibição da formação do biofilme pelos extratos. Colunas 8 e 9- Controle de crescimento das leveduras. Coluna 7 inteira- Controle de clorexidina $0.12 \%$.

Fonte: Noara Taline Pereira dos Reis (2011).

\section{CONCLUSÃO}

Os extratos hidroetanólicos das folhas de Psidium guajava L e Myrciaria cauliflora, utilizados neste experimento, não apresentaram ação inibitória no crescimento e na formação de biofilmes por Candida albicans.

\section{REFERÊNCIAS}

AIDS - Manifestações Orais. Infecções fúngicas. Disponível em: $\leq \mathrm{http}$ ://www.odontogeral.hpg.ig.com.br/aids manifestbucais.html>. Acesso em: 19 maio 2003.

ALONSO T. Tratado de Fitomedicina: bases clínicas y farmacológicas. Buenos Aires: ISIS Ediciones SRL, 1998. 
ALVES M. P.; LEITE H.A.S. P.; PEREIRA V. J.; PEREIRA F. L.; PEREIRA S. V. M.; HIGINO S. J.; LIMA O. E.. Atividade antifúngica do extrato de Psidium guajava Linn. (goiabeira) sobre leveduras do gênero Candida da cavidade oral: uma avaliação in vitro. Revista Brasileira de Farmacognosia 16(2): p. 192-196, Abr./Jun., 2006.

ASCHERI, D.P.M.; ASCHERI, J.L.M; CARVALHO, C.W.P. Caracterização da farinha de bagaço de jabuticaba e propriedades funcionais dos extrusados. Ciência e Tecnologia Alimentar Campinas, v.26, n.4, p.1-9, 2006.

BEIGHTON D, DECKER J, HOMER KA. Effects of chlorhexidine on proteolytic and glicosidic enzyme activities of dental plaque bacteria. J Clin Periodontol 18: 85-89, 1991.

BOTELHO, M.A. et al. Antimicrobial activity of the essencial oil from Lippia sidoides, carvacrol and thymol against other pathogens. Brazilian Journal of Medical and Biological Research, v.40, p.349-56, 2007.

BRUNINI, M.A. et al. Influencia de embalagens e temperatura no armazenamento de jabuticabas (Myrciaria jabuticaba Berg) cv "sabará". Ciência e Tecnologia Alimentar Campinas, v.24, n.3, p.378-83, 2004.

DAVEY, M.E.;O'TOOLE, G. A. Microbial biofilms: from ecology to molecular genetics. Microbiol. Mol. Biol. Rev. v. 64, p.847-867, 2000 .

JARVENSIVU, A. ; HIETAMEN, J. ; RAUTEMMA, R. ; SORSA, T. ; RICHARDSON, M. Candida yeast in chronic periodontitis tissues and subgingival microbial biofilms in vivo. Periodon. Oral Microbiol. v.10, p106-112, 2004.

KORNMAN KS. The role of supragingival plaque in the prevention and treatment of periodontal diseases: a review of current concepts. J Periodont Res (Suppl.): 5-22, 1986.
MACEDO-COSTA, M.R. Atividade antimicrobiana e antiaderente de Mimosa tenuiflora (Willd) Poir e Myrciaria cauliflora Berg sobre bactérias do biofilme dental. p. 72, 2008. Monografia (Graduação em Odontologia) - Universidade Federal da Paraíba, João Pessoa.

MACEDO-COSTA, M.R; DINIZ N. D. ; CARVALHO M. C. ; PEREIRA V. M.S. ; PEREIRA V. J. ; HIGINO S. J.. Eficácia do extrato de Myrciaria cauliflora (Mart.) O. Berg. (jabuticabeira) sobre bactérias orais. Revista Brasileira de Farmacognosia 19(2B): p. 565-571, Abr./Jun., 2009.

MARSH, P.D. Dental plaque as a microbial biofilm. Caries Res. v.38, p 204-211, 2004.

MORAN J, ADDY M., NEWCOMBE RG, MARLON I. A Study to assess the plaque inhibitory action of newly formulated triclosan toothpaste. J Clin Periodontal 28: 86-89, 2001. NIKAWA, H,; YAMASHIRO, H.; MAKIHIRA,S.; NISHIMURA, M.; EGUSA, H.; FURUKAWA, M.; et al. In vitro cariogenic potential of Candida albicans. Mycoses. v.46, p.47 1-478, 2003.

PESSINI GL, Holetz FB, Sanches NR, Cortez DAG, Dias-Filho BP, Nakamura CV. Avaliação da atividade antibacteriana e antifúngica de extratos de plantas utilizados na medicina popular. Rev Bras Farmacogn, 13(Supl. 1): 21-24, 2003.

RAMAGE, G.; SAVILLE, S. P.; THOMAS, D.P.; LOPEZ-RIBOT, J.L Candida biofilms: an update. Eukaryot. Cell. v.4, p.633638,2005 .

REYNERTSON, K.A. et al. Bioactive depsides and anthocyanins from jaboticaba (Myrciaria cauliflora). Journal of Natural Products, v.69, p.1228-30, 2006.

RODRIGUES JÚNIOR AL. Redução do índice de placa com listerine. Avaliação do índice de placa em relação ao uso de listerine e/ou escovação. $\boldsymbol{R} \boldsymbol{G O}$ 46: 101-108, 1998. 
SATO J, Goto K, Nanjo F, Kawai S, Murata K 2000. Antifugal activity of plant extracts against Arthrinium sacchari and Chaetomium funicola. J Biosci Bioeng 90: 442-446.

TÔRRES AR, Oliveira RAG, Diniz MFFM, Araújo EC 2005. Estudo sobre o uso de plantas medicinais em crianças hospitalizadas da cidade de João Pessoa: riscos e benefícios. Rev Bras Farmacogn 15: 373-380.

VENDRUSCULO GS, Rates SMK, Mentz LA 2005. Dados químicos e farmacológicos sobre as plantas utilizadas como medicinais pela comunidade do bairro Ponta Grossa, Porto Alegre, Rio Grande do Sul. Rev Bras

Farmacogn 15: 361-372.

YANAGIDA A. Inhibitory effects of apple polyphenols and related compounds on cariogenic factors of mutans streptococci. Journal Agricola Food Chemical 48:56665671, 2000.

WAKIMOTO, N.; NISHI, J.; SHEIKH, J.; NATARO, J.M.; SARANTUYA, J.; IWASHITA, M.; MANAGO, K.; TOKUDA, K.; YOSHINAGA, M. AND KAWANO, Y. Quantitative biofilm assay using microtiter plate to screen for enteroaggretative Escherichia coli. Am. J. Trop. Med. Hyg., 71, p.687-690,2004. 